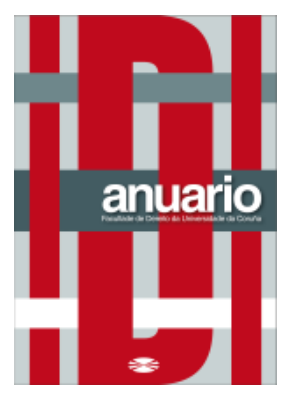

Anuario da Facultade de Dereito da Universidade da Coruña

Vol. 20 (2016), pp. 492-493

ISSNe: 2530-6324 || ISSN: 1138-039X

DOI: https://doi.org/10.17979/afdudc.2016.20.0.1954

\title{
J. CABEZA PEREIRO, Ensayo sobre el trabajo precario y las personas vulnerables, Laborum (Murcia, 2015), 184 págs.
}

\author{
Alberto ARUfe VARELA \\ Catedrático acreditado de Derecho del Trabajo \\ Facultad de Derecho. Universidad de A Coruña
}

Si hubiese que calificar con sólo una palabra esta monografía apasionante e inquietante (e incluso, desasosegante) del Catedrático vigués de Derecho del Trabajo, Prof. CABEZA PEREIRO, yo hablaría de su radical originalidad. Efectivamente, la crítica del momento laboral que vivimos a día de hoy en la Europa aún unida de los veintiocho (con todos sus sobresaltos financieros, no solamente los bancarios, con toda la presión inmigratoria que soportamos, con toda la austeridad laboral que se nos receta desde Bruselas, y con todos los cambios geoeconómicos que se fuerzan por nuestros amigos yankees desde el otro lado del Óceano, haciendo cada vez más irrelevante, por ejemplo, el consumo de derivados del petróleo, etc.), si efectuada desde el punto de vista británico (en el momento en que esto escribo, además, no sabemos todavía si el «Brexit» acabará teniendo o no su aportación «constitucional», tan propia de todos los intentos secesionistas, a la historia de la Unión Europea), tapa huecos y abre brechas en el movimiento crítico general, al que casi todos los europeos unidos nos adherimos, cuando reflexionamos sobre el presente y el futuro laborales de la Unión Europea. Por supuesto, el Prof. CABEZA PEREIRO no oculta en absoluto este enfoque «británico» suyo de su tema, constando en este libro, publicado por la editorial Laborum, que ha sido el fruto de una larga estancia suya de investigación en la Universidad de Hull, codedicándoselo incluso a un conocido experto en Derecho internacional y comparado del Trabajo, que todavía continúa profesando (con todas las virtudes del catedrático senior) en dicha Universidad inglesa.

Nuestro autor califica su obra, de más de ciento ochenta páginas, y casi quinientas notas al pie de ellas, con el calificativo de «ensayo». En mi opinión, quizá quiera justificar el autor con este calificativo - inusual en el panorama jurídico laboral español, cuando de publicar monografías se trata- el hecho de que las fuentes de conocimiento primariamente manejadas en su obra no sean ni legales ni jurisprudenciales, sino fundamental (y casi exclusivamente) doctrinales, escritas en lengua inglesa. Entre lo mucho y lo bueno manejado y citado por nuestro catedrático 
vigués, yo destacaría dos obras muy indicativas del peculiar background doctrinal en que el mismo se ha movido, para así fundamentar su trabajo. De un lado, la monografía dirigida por C. COSTELLO y M. FREEDLAND, sobre Migrants at work: Inmigration and vulnerability in Labour Law, Oxford University Press (Oxford, 2014), que incide frontalmente sobre el tópico de la vulnerabilidad, que el Prof. CABEZA PEREIRO traslada incluso al título de su trabajo. De otro lado, el artículo de V. GASH y F. McGINNITY, de marcada metodología interdisciplinar-comparatista, titulado «Fixedterm contracts - the new European inequality? Comparing men and women in West Germany and France», por apuntar directamente a lo que todos y en todas partes entenderíamos - sin mayores matices - por trabajo precario, una idea que asimismo ilumina el título de la monografía aquí recensionada. Y es que ambos trabajos ilustran sobre la existencia de personas laboralmente vulnerables en el Reino Unido, sobre el hecho de que la Unión Europea parezca encontrarse sobrepasada por este tipo de acontecimientos, e incluso - siempre desde el peculiar punto de vista británico-, por el dato de que en la Europa unida manden y cuenten, en realidad, sólo dos grandes países continentales (y si se nos apura mucho, sólo uno de ellos), a lo cual — como es lógico - no se resignan ni los ciudadanos, ni los políticos, ni tampoco los académicos británicos. Remito, para una crítica feroz (y original) del Derecho social de la Unión Europea, tan natural desde la perspectiva de las fuentes doctrinales manejadas por nuestro catedrático vigués, al apartado Sexto de su obra, sobre «El enfoque del trabajo vulnerable en la Unión Europea».

Creo que no resulta fácil para un jurista continental europeo poder llegar a encariñarse con el Derecho inglés. Puse de relieve los porqués de ello en un artículo mío del año pasado, publicado en la Revista de Derecho de la Seguridad Social, en donde estudiaba las estructuras normativas del Derecho inglés de la Seguridad Social. En él, intentaba remontarme sobre el tópico de que el Derecho inglés no es Derecho legislado, pero viéndome obligado a tener que despejar al mismo tiempo si debía hablar de Derecho «inglés», o si, por el contrario, lo más procedente era referirme al Derecho «británico». Allí se encontrará la mención de la línea doctrinal española (iniciada por el Prof. ALONSO OLEA, continuada por el Maestro de nuestro autor, aumentada luego por el Prof. GALIANA MORENO, y vivificada y mantenida con el mismo nivel de excelencia académica, en la generación presente, precisamente por nuestro querido y admirado catedrático vigués). Contaba allí que el Prof. CABEZA PEREIRO había optado por el calificativo de «británico», con ocasión de un artículo suyo sobre jurisprudencia laboral de la Cámara de los Lores sobre vacaciones, publicado en el volumen II (2010) de nuestro Anuario Coruñés de Derecho Comparado del Trabajo, que me pareció entonces y me sigue pareciendo ahora un artículo entrañable. A día de hoy, nadie mejor que el Prof. CABEZA PEREIRO, jurista continental, pero también profundamente encariñado con el Derecho laboral de Gran Bretaña, para dar a conocer con toda solvencia científica una literatura jurídica tan significativa, pero al mismo tiempo tan poco conocida en nuestro país, como es la literatura jurídico laboral (y jurídico social) que él califica de «británica». Lo vivió en su etapa formativa como doctorando, le ha sacado sus frutos y su partido en sus muchas publicaciones posteriores sobre comparaciones jurídicas bilaterales (en las que uno de los términos de la comparación es el Derecho británico, siempre tan familiar para él) y lo culmina con esta monografía (marcada por el momento desasosegante que nos ha tocado vivir), original $a b$ radice, que animo a cualquier lector interesado en la problemática de la justicia social a desgranar y leer. 